Law and Visual Jurisprudence 4

Series Editors: Sarah Marusek. Anne Wagner

Francesco Mangiapane

Tiziana Migliore Editors

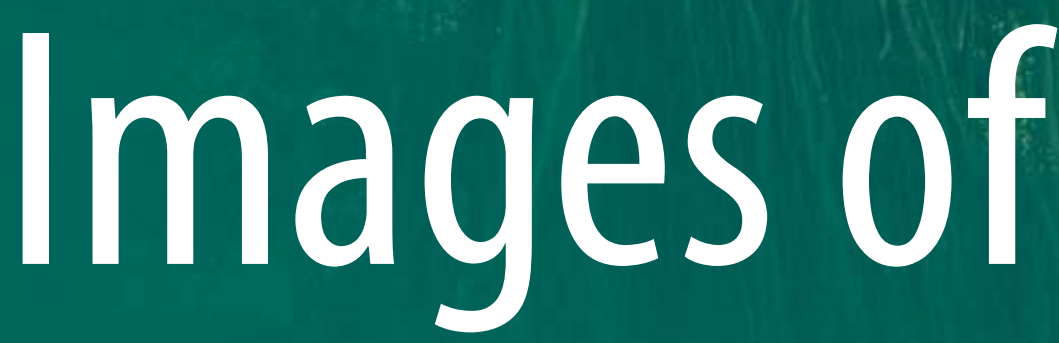

Europe

The Union between Federation and Separation 
Francesco Mangiapane - Tiziana Migliore Editors

\section{Images of Europe}

The Union between Federation and Separation 


\section{Editors}

Francesco Mangiapane

University of Palermo

Palermo, Italy
Tiziana Migliore

University of Urbino

Urbino, Italy
ISSN 2662-4532

Law and Visual Jurisprudence

ISBN 978-3-030-69239-1

https://doi.org/10.1007/978-3-030-69240-7
ISSN 2662-4540 (electronic)

ISBN 978-3-030-69240-7 (eBook)

(C) The Editor(s) (if applicable) and The Author(s), under exclusive license to Springer Nature Switzerland AG 2021

This work is subject to copyright. All rights are solely and exclusively licensed by the Publisher, whether the whole or part of the material is concerned, specifically the rights of translation, reprinting, reuse of illustrations, recitation, broadcasting, reproduction on microfilms or in any other physical way, and transmission or information storage and retrieval, electronic adaptation, computer software, or by similar or dissimilar methodology now known or hereafter developed.

The use of general descriptive names, registered names, trademarks, service marks, etc. in this publication does not imply, even in the absence of a specific statement, that such names are exempt from the relevant protective laws and regulations and therefore free for general use.

The publisher, the authors, and the editors are safe to assume that the advice and information in this book are believed to be true and accurate at the date of publication. Neither the publisher nor the authors or the editors give a warranty, expressed or implied, with respect to the material contained herein or for any errors or omissions that may have been made. The publisher remains neutral with regard to jurisdictional claims in published maps and institutional affiliations.

This Springer imprint is published by the registered company Springer Nature Switzerland AG.

The registered company address is: Gewerbestrasse 11, 6330 Cham, Switzerland 


\section{Contents}

Many Images for a Continent. An Introduction . . . . . . . . . . . . . . . 1

Francesco Mangiapane and Tiziana Migliore

Part I Perspectives and Destinies

The European Flag According to Paolo Fabbri . . . . . . . . . . . . . . . . 15

Francesco Mangiapane and Tiziana Migliore

A Proper Name for a Proper Union. Europe's Mythological Model . . . . 27

Tiziana Migliore

European Identity and the Sexual Function of Erasmus Program.

Nomadism, Bilingualism and "Swiss Language" . . . . . . . . . . .

Claudio Paolucci

Exercising the European Essence. From Epistemology to Ethics

Simona Chiodo

Geopolitics and Images: From Images to Discourse . . . . . . . . . . . . . .

Giuseppe Bettoni

The "Decline of the West" as a Semiotic Strategy Against a European

Union

Frank Jacob

The European Union and the Spirit of Family in the Vision of Pope

Francis

Paolo Peverini

\section{Part II Borders and Limits}

National Self-Determination and the Limits of Europe

Franciscu Sedda 
Europe in the Balkans: Weak Normative Power Meets Pallid

Legitimacy

Eric Gordy

The Inner Border as the Construction Site to Build a Hybrid Europe.

The Case of South Tyrol . . . . . . . . . . . . . . . . . . . . . . . . 153

Valeria Burgio

“From an Uncertain Border". Double, Existential and Discursive, European Crisis: Changes of Glance, Between Migrants Crisis and Climate Change .

Federico Montanari

Part III Narratives and Representations

"So Disarmingly European”. Eurovision Song Contest

and the European Identity . . . . . . . . . . . . . . . . . . . . . . . . . 185

Lucio Spaziante

Europe's Cosmopolitan Identity. Images of Unity in Diversity

in the Euro.

Monica Sassatelli

European Utopics. On the Interreg Central Europe Cooperation

Programme .

Maria Cristina Addis

European Politics of Food Origin. A Semiotic Analysis of Geographical

Indications

Davide Puca 


\title{
Geopolitics and Images: From Images to Discourse
}

\author{
Giuseppe Bettoni
}

\section{Geopolitics and Representation}

The term geopolitics has multiple applications, even within the field. Lately, it has become extremely popular in the media and most of the times it's used in an absolutely incorrect manner. How many times have we read headlines such as: "The geopolitics of weapons" or "The geopolitics of oil", even "The geopolitics of football"... None of these headlines are clear on what the ensuing content will be nor do they offer a constructive approach.

Let's start with the words and their meaning. How do we characterize geopolitics? Below I will list some definitions, most of which are common in the scientific community, and I will end with the one that has best utilized symbols and images to deepen the relationship with geopolitics.

The first definition we introduce defines geopolitics as the "relations between [...] countries, or to the politics of colonization of vast areas by world powers" (O'Loughlin 1994). This is the indication that John O'Loughlin provides in his dictionary, where he draws a fairly comprehensive overview of geopolitics but which objectively appears, as I will detail later, reductive compared to the quantity of interests actually covered by geopolitics. Overall, O'Loughlin's discourse centers on how geopolitics deals with political relations between states as they happen primarily, though not exclusively, on a global scale.

O'Loughlin defines three possible types of geopolitics:

\footnotetext{
G. Bettoni $(\bowtie)$

University of Rome "Tor Vergata", Rome, Italy

e-mail: giuseppe.bettoni@uniroma2.it 
1) The geographical scope of foreign policy, which splits the focus of geopolitics in

a. the study of the localization of peoples and the distribution of diversity (and in particular the study of the diversity of their localization). This study provides data collection for any type of foreign policy action;

b. the implementation of actions necessary to achieve specific objectives;

2) The geopolitics of the various states (of the United States, of Italy etc.) as a question of worldview from within one's own country as a starting point as well as highlighting a country's own interests within the global political chessboard. From this perspective, obviously every geopolitics is different in the eye of a different state, because the global reality will be read in the light of the national interests of each state;

3) A "critical geopolitics" which stems from the belief that geopolitics has always been linked to power as an instrument of support. Critical geopolitics simply interprets official positions to understand well what are the goals of Power, hence offer alternative readings and assessment.

John Agnew, although looking back at the most remote origins of the discipline, immediately brings us up to date with a second definition of geopolitics. Agnew recalls that the concept of geopolitics rose in the nineteenth century, simply as an allusion to the geographical representations in the field of international politics in the world. However, since the 1990s the constant and confusing use of the word "geopolitics" has led to its employment in issues of immigration, international relations, as well as electoral geography. This "expropriation" of the term allows for a thoughtful reflection on its meaning and on its implications. In this regard, Agnew tries to outline the first contours of geopolitics as the analysis of geographical hypotheses, designations and understandings that are part of "world politics" (Agnew 1998). He directs our attention to what we might call the first traces of geopolitics, particularly with respect to the politics of certain states in the sixteenth century. He says that in reality, beyond the exact rise of geopolitics, it has gained ground as a structural presence in the field of geography ever since the "world" was conceived as a whole unit. Agnew identifies four geopolitical scales in order of importance:

1) world, where it is conceived in its entirety;

2) international, which concerns relations between two or more states, though not always on a global level;

3) national, which is specific to each state;

4) regional, relating to the internal parts of the various states.

To date, French geographer Yves Lacoste offers the most complex definition of geopolitics. According to him, any situation in which two or more political actors compete for a specific territory is considered geopolitical. In this competition, the populations who inhabit the territory, or who are represented by the sparring actors, must be involved in the dispute by the deployment of mass communication tools. I'd 
like to focus on this definition (Lacoste 1993) to follow up on my explanation and above all on Lacoste's concept of representation.

To Lacoste, representation denotes two specific things:

1) the drawing of a map. Geopolitics deals with antagonisms between actors for territorial issues, and therefore its main representation tool is the geographical map. A paper map is an instrument widely accepted as objective, however it's really a subjective communication tool, since it never represents a territory accurately, in fact it is always the representation of a specific idea of territory. On the other hand, the map is still irreplaceable today since no other instrument can represent a territory in the same manner. Its subjectivity means that it is a tool in the hands of the actor who wants to make practical use of it, an ideal tool in the hands of power or a counterpower. Even the geographical maps commonly found in a geographical atlas are subjective, they are a one-sided choice to show a world which, in any case, is impossible to see in its entirety.

2) a theatrical act. Truly, in an actor's communication strategy for the control of a certain territory, dramatization is a common practice, and the role of the media and images is fundamental. We use photographs to convey emotions that support the strategies we want to pursue. For example, to expose the unscrupulousness of oil companies we show images of environmental damage; or to unmask the indifference of governments to migratory flows, we use images of suffering migrants. Geopolitics relies heavily on communication and the media. There are numerous periodicals which use maps with specialized editorial offices more and more (newspapers such as Le Monde, The Guardian, the New York Times, among others). However specialized cartographic periodicals exist, such as the French periodical Carto, which uses cartography to deal with current issues. Lacoste's definition emphasizes the role of discussion in the population and the role of representation in the media.

We cannot talk about geopolitics and not refer to Gearóid Ó Tuathail, whose work has stimulated that current of thought called critical geopolitics and which is of great importance within this current. Critical geopolitics is inspired by a famous work by Yves Lacoste that led to a profound discussion about the role of geography and by extension of geopolitics. Ó Tuathail's work is particularly relevant in regards to the role he attributes to representation, which he calls discourse. The tie between geopolitics and discourse is extremely strong:

It is only through discourse that the building up of a navy or the decision to invade a foreign country is made meaningful and justified. It is through discourse that leaders act (Ó Tuathail and Agnew 1992).

This article highlights how in 'practical' geopolitics, globalization creates new connections and especially new descriptions of the world. It is precisely this type of "description" that interests us in this context because geography is above all the subjective description, and therefore the subjective interpretation, that each of us makes. 
Ó Tuathail returns directly to Yves Lacoste's work in an article that aims at rereading geopolitics in light of Derrida's contribution to deconstructionism. The construction of concepts such as East or West, Third World, etc. are all geographic concepts, and yet they're built to convey precise social meanings; Ó Tuathail's work shows geography as a language and social knowledge that does not only include "[...] academic works but mass-media-generated geographical clichés and images [...] Geography is taught not only in classrooms but also in films, newspapers and advertisements" (1994).

In the work of each of these scholars, any talk about geopolitics, and ultimately about geography, means mostly talking about "representation" as a description of the world, or possibly of a specific disputed territory, where the construction of the "discourse" means calling this territory into existence, and present it as a social construct. From the media viewpoint, such construct comes in miscellaneous forms. I have already discussed about Ó Tuathail's "discourse" where, actually, no reference is made to a simple oral speech: "[...] It is not simply speech or written statements but the rules by which verbal speech and written statements are made meaningful. Discourses enable one to write, speak, listen and act meaningfully" (Ó Tuathail and Agnew 1992). Discourse is then a social construct that may be conveyed through different means. However, a narrative is proposed, and in geopolitics, that narrative is one of many, in clear opposition to that of its adversaries.

As Lacoste himself says, representations are basically ideas (Lacoste 1993). We have catalogs of these representations which attempts to organize large quantities of representations - historical, geographic, cartographic - or representations proceeding from political and philosophical ideas (Loyer 2019). Naturally, words and images play an important role. At first Loyer herself remembers how certain words are in themselves a representation. We often hear about "rights" or "people" with a geopolitical goal, the affirmation of rights and power; or in circumstances concerning internal actions within a state, such as local development policies which tend to be conflicting choices since opposite actors almost always have separate visions of development. For example, an actor who would like industrial growth opposes naturalistic and agricultural improvements. Very often in these cases we hear about the "vocation" of the territory, which is a particularly inadequate statement, as territories do not have vocations but potential, rather. Yet the term "vocation" serves to establish that strategy, make it almost "natural", "inevitable". In geopolitics many times the "representations" are false or refer to unclear ensembles of territories. Similarly, when discussing identity, the assumption is that we all know what it means. In reality, each of us has a discrete idea of identity and even more discrete is the definition of territory that is attributed to it; and yet numerous representations exist around this term, such as cartographs, photographs, and several iconographic discourses and references. In geopolitics, we consider the "nation" as the major geopolitical representation mostly because it is difficult to define exactly what a nation is. We know that it is a collective imaginary construction made with a selection of precise historical facts and which brings together various groups (Lacoste 1998), with the goal of making sense of a state which, ultimately, will have to act in the name of that nation for tax collection, for example, or construction 
of certain public services, and other matters. Understandably, this also requires the identification of a territory on which that given nation claims to have certain legitimacy.

The "nation" is a topic that arouses great debates between experts for its complicated definition but also for the desire of each community to create one, as if being individuals meant therefore partake of a community which must, by force of things, come together as a nation. Hence the search for those ingredients that we consider necessary, such as symbols, languages, cultural products, historical constructs, definition of a territory with the composition of a whole cartographic imaginary. Existence is built as a nation, and, in relation to that construct, a position is defined in relation to the planet: I exist as an individual and therefore I am part of a nation on a territory (it doesn't matter if I own and control this territory or not, as in the case of the Kurds or the Palestinian Arabs). In relation to identity formation of the nation to which I belong, discourses are developed towards "others", be as it may, those who are in and those who are out; which historical events are significant for a given nation, such as which images, which symbolic places, which are all built for an "unlimited" nation. This concept of nation is perhaps the most geopolitical concept; a robust idea that witnesses many territorial disputes, precisely because the concept of nation is fluid, its definition is never clear. Yet antagonistic representations are particularly powerful and convincing in regards to the territory and its inhabitants. If we take the idea of an Italian nation for example, the notion of a territory that falls within the borders of the state is not sufficient. At the beginning of the Italian Unification, some believed that territories such as Corsica, Dalmatia and Istria, even Nice and Malta, were integral part of the Italian nation, even though the membership of these territorial areas in the Italian nation was questionable. Still today, many consider those territorial area as "Italian". Within the European Union, the concept of "nation" is up to those who use it, either in opposition or in favor of a stronger EU. These are very powerful concepts which unite large communities of people despite the differences which may exist among them regarding the nation's identity and cultural content.

\section{Toponyms and Geopolitics}

A representation can be assembled with an assortment of tools, then. I began with discourse as intended by Ó Tuathail and with words, as Loyer indicated. The names of places are themselves a topic of geopolitical contention and for this reason it seems right to mention some of them as an example, while keeping in mind that locations bear names according to the language we use, not just in terms of changing pronunciations for the same name or of different versions according, again, to the language used. Very often in world languages, the meaning attributed to a certain place varies according to one's own "world view". So, we name places from within our world view and our geographical position; moreover, we choose those names either due to historical events which we consider important for our culture or we 
name them to indicate a geographical position in relation where we live and to our vision of the world from our own vantage point.

Toponyms are not chosen haphazardly, and in geopolitics, as we explore below, that choice is an essential step for the attribution or legitimization of a territory or a sea. Often, however, portions of a body of water are not named specifically, which brings about many disputes-so many, in fact, that they'd fit in an "Atlas of contested toponyms". One of the most famous, particularly in recent years, is that of the Persian Gulf, also known as Arabian Gulf.

In the late 1950s, Iran protested vehemently against a decision made by Iraq and other Arab countries, as well as by Great Britain, to adopt the official name of Arabian Gulf instead of Persian Gulf, which was the traditional denomination. In particular, Iran's Shah Mohammad Reza Pahlavi addressed a formal protest to Iraq, which was governed at the time by Abdul Karim Qasim, who had led the coup in 1958. To provide a context, let's establish now that the naming the Gulf - a sea of over 240,000 $\mathrm{km}^{2}$ — "Arabian" was unusual. In fact, up to that moment no one had questioned the denomination "Persian Gulf" (not even the Arab countries who participated in the re-naming of the Gulf, as we will see shortly). Instead, a representative of the United Kingdom in that area in the 1930s, Sir Charles Belgric, gave legitimacy to a new claim in 1966 when he wrote that the residents of the Arab countries would prefer the name of the Arabian Gulf to that of Persian Gulf. Clearly the book did nothing but complete information that Belgric had been working on for years, and yet it conveyed a "novel" idea to the Arab populations located on the Gulf shores. From then on, the Arab Gulf appellation resonates more and more in both British and Arab official documents.

Yet earlier documents always and only reported the appellation "Persian Gulf". Many documents prior to the Christian era describe a Fars or Pars area (which the word 'Persian' is a derivative); among these, the first document to mention the Fars/ Pars was written by Darius I, emperor of the Achaemenid dynasty, whose ships entered the Red Sea, after descending into the Indian Ocean on the Indus River, and circumnavigating the Arabian Peninsula. On the site for the excavation of a canal, where the Suez Canal is located today, Darius describes the Persian Gulf with these words: "I ordered that a canal be dug that will connect the river that flows in Egypt with the sea that reaches Persia" (Erodotus 2000).

The Greeks already called the Gulf persicos sinos or sinos persicos and the Greek geographer Strabo in the first century AD describes the Arabs as a population who lives "[...] between the Red Sea and the Persian Gulf" (Strabo 2002). The denomination "Persian" for this portion of the Gulf appears certainly more legitimate from the historical point of view, above all because Strabo was not himself Persian. However, even more interesting is the fact that the same Arabic sources always use the denomination "Persian" and never "Arabian". Scholars of the caliber of Ibn Batouta, Nasser Khosrow, Abou Rayhan Al-Birouni or, again, Ibn Balkhi have always referred to a "sea of the Persians" with abundant descriptions.

To deal with the "Arabian Gulf" denomination, the Iranian customs authorities began by refusing all goods labelled "Arabian Gulf". At international meetings, Iranian diplomats never hesitated to show their opposition by abandoning crucial 
meeting sessions. At this point it is necessary to explain not so much the strategies as the reasons for the choices that led to such opposition. One could argue simply that a name does not change a place.

In point of fact, a name creates a place, and defines it. A place probably (only probably) exists absolutely (that is, beyond how it is indicated), yet at the same time its existence is relevant because it is defined in relations to humans and other communities. The toponym's significance has meaning for the community or communities in terms of what it represents. For humans, places are like words: they are important for what they represent, and therefore they are not only a vehicle for content but words also participate in their own use, in their own content. For this reason, toponyms are stronger than who controls the place. In our example, the British used a strategy of discord to destabilize Iranians and especially their influence on the Gulf. After the British, the United States began the same destabilization strategy of the Persian/Arab Gulf to increase their influence in that area in the 1980s.

Among other interesting geopolitical cases of toponyms, it is worth mentioning two more and which concern bodies of water although in different ways. Both cases involve Japan yet with slight variations.

The first case concerns a dispute with Korea regarding the body of water which separates the Japanese archipelago from the Asian continent, and which is commonly known as the Sea of Japan. I should immediately point out that this is a "strong" toponym, where the name indicates belonging ('sea belonging to Japan'); understandably, the populations who live by that body of water feel expropriated. This has not been a long-standing dispute, quite the opposite. It began in 1992 when North and South Korea jointly proposed the appellation of Eastern Sea at a United Nations conference on the standardization of geographical names. This quarrel experienced a lively revival when in 2002 the International Hydrographic Organization (IHO) sent an official letter to all its seventy-two members in which they were asked to vote for one of the two names so as to be included in the definitive volume of "Limits of the Oceans and Seas" (which remains unpublished!). The two Korean governments pointed out that the name "Sea of Japan" was imposed to the world when the Korean peninsula was occupied by the Japanese at the time of the Empire. According to the Koreans, in fact, "East Sea", "Eastern Sea" or "Korean Sea" are much older than what is used today. The Koreans also point out that the registration of the toponym "Sea of Japan" took place at the IHO in 1929, in the middle of the Japanese colonial era, when no one in Korea could have contested this choice.

The Japanese on their end declare that "Sea of Japan" is as old as "Sea of Korea", so they do not contest the Korean claim. In their own support, they cite the eighteenth-century Atlas by explorer Jean-François de La Pérouse, which reports "Sea of Japan" therefore confirming that denomination as existing prior to the Japanese expansionist period. By now all the Korean atlases show the word Tonghaee, which means East Sea, however the Koreans would settle for a double denomination: "East Sea/Sea of Japan". Sadly, the issue is far from being resolved. It is possible to empathize with the Korean révanchiste feeling, especially when remembering the abuse Koreans had to suffer at the hand of the Japanese. Moreover, the imposition of one country's own symbology on a place that is considered part of 
one's own land defines relations irretrievably, as in the case of North and South Korea with Japan. Remarkably, on the one hand stands the Japanese vision of possession whereas, on the other, an anti-peripheral vision by the Koreas, which is anti-peripheral because by calling this body of water "East Sea" no single country takes ownership of it, even though it was known at some point as the Korean Sea. "East Sea" projects an expansive vision of one's own land: this body of water pertains to the East instead of to Korea alone. Ultimately, a toponym affirms a vision of the geographical space in which we find ourselves, we live and interact.

The second case we mentioned earlier involves Japan as well. The South Kuril Islands, known in Russian as Курильские острова́ (Kuril'skie ostrova) were occupied by the Red Army at the end of the Second World War. As a reminder, Tsarist Russia granted those islands to Japan in 1875 in exchange for the Kamchatka peninsula. However, given their high strategic value, the Moscow government decided to re-occupy them militarily since, coming from the Okhotsk sea into the Pacific, Russian ships would have no other way but to pass through the Kuril Islands; the military occupation granted the Russians constant freedom of movement. However, the Japanese did not give in easily as those islands, which they originally called Chishima islands, 千島列島 (Chishima rettō), and alluded to the ainu people of the island of Hokkaido. However, since 1956, which is when they tried to resolve the dispute, even though a peace treaty has been a long time coming, they prefer to call them Hoppo ryodo, "northern territories". Unlike the situation with Korea, this denomination indicates an appropriation via an adequate toponym indicating a possession, a projection, a "representation" of the geographical context, much like the representations we described at the beginning of this text.

All these cases, the Persian/Arabian Gulf, the Sea of Japan/East Sea and Kuril Islands/northern territories, are different amongst themselves and yet they all express a desire to give a "representation" of a specific territory that is most unlike that by the opponent. All these representations are valid, and their shared goal is to offer the places in dispute a unique symbolism. The debate between center/periphery, history, government - all these factors are involved in choosing a toponym and become absorbed in its symbolic value.

My goal here was to show how toponyms both as choices and attributions give us insights both relevant for geography and the second for geopolitics.

1. Geography literally describes the world but also interprets it. We observe our surroundings and describe what we see according to what features stand out to each of us. This means that each of us makes one's own geography depending on who we are, how we live, what values and culture we possess, which social networks are important to us, etc., and this applies to every location on the planet. In the case of toponyms, naming a place is the result of this interpretation of the world: we name a place in relation to how we define our place and our culture and also in regards to what the important things are in our perception. Ultimately this individual design can become collective. An example of this is the concept of the Orient which, as Edward Said has shown, is a social construct with the specific 
goal of making its exoticism, delayed development and dangerousness a justification for its colonization (Said 1978).

2. Naming a place, as in the examples we have shown, becomes an eminently geopolitical gesture. This is because, as expressed by Lacoste as well as by Ó Tuathail and Agnew, it is a representation of the world that places one of the antagonistic parts as legitimate with respect to that disputed territory. Calling the Sea in question "East Sea" means defining it in relations Korea's location, and therefore giving that body of water a role on Earth from the vantage point of Korea; even though it's not called "Korean Sea", it does exist in relation to Korea's geographic location. In the struggle between actors for the control of the territory, naming a place becomes a technique for one actor to justifiably have the right control or influence that disputed territory than another actor. Therefore, with a name we build a geopolitical representation of the world.

\section{Visual Representations in Geopolitics}

\subsection{Cartography}

Images are an inseparable element of geopolitics, as we have seen previously, and variably so.

The first element that we must consider is that of cartography, which, in very simple terms, are drawings that should remind our conscience and our culture of a certain vision of the territory. The scholarship on the technical qualities of cartography is extensive and includes work by the Critical Cartography movement. Since World War II, cartography no longer qualifies as a science that studies a reproduction of "reality" on paper, nor are geographical maps any longer divided between scientific and standard maps. The focus has shifted from how an object or phenomenon is "mapped" to how the "mapping" of a phenomenon may influence its observers, and how it produces values and identities (Pickles 2004). Maps have always been an instrument of power. It is no coincidence that in Soviet countries sales of maps were prohibited to the general public and only granted to specialists. Maps are an instrument of power even when they become accessible to all because the cartographs express visions of a specific territory, which contain strategies and an interest, either by the cartographer or by of those who have charged the cartographer with making a specific geographical map (Wood 1992). Practically speaking, cartography also is a unique research field for university students, where the cartographic message is at once academic and pragmatic: any geographical map conveys a discourse, and therefore constitutes an object of study which conveys visions, and fosters a sense of identity (Harley 1988). A few years earlier, Lacoste had reflected on the power of maps: "A map implies a certain political and scientific mastery of the represented space, and is an instrument of power over the people who live there [...] The map is the tool to dominate space and men" (Lacoste 1976). 
A geographical map is our first iconographic tool here because Geopolitics is first of all made of "geography". Nonetheless, as I described earlier when explaining the concept of discourse, images play an increasingly important role, especially in a historical time where we are bombarded by a plethora of images, photographs, drawings, videos, symbols.

\subsection{Images and Monuments}

Today the current state of affairs-political and geopolitical-is inevitably connected to images that may relate to a territory, as geographical maps do, however, as I show below, these images may be Landscapes built to convey sets of values, or to represent certain geopolitical situations. An emblematic case is the flow of migrants who cross the Mediterranean from Africa to reach Europe. Depending on the point we want to make, we may use different photographs with diverging dramatizations: from death to invasion, photography supports any kind of representation. Ultimately, one will never know the motivation and the goal of a given photograph, however by framing it within a context and a discourse, the photo will acquire a specific value which may diverge from what the photographer intended. Photographs contain a metaphorical vision of reality. Korzybski (1998) reminded us that "a map is not the territory", which also applies to photographs as representations of a reality which is first and foremost interpreted subjectively. If it is true that the map is representation of the earth as much as the cartographer's interpretation, similarly a photograph is primarily a representation of reality chosen by the photographer who, among other things, gives that image away so that it can become a representation of reality according to someone else's interpretation. Regardless, a representation is never the object represented nor can it ever replace the actual object. However, images are very powerful tools for the affirmation of values, which we find difficult to question. Many examples confirm how much the use of photographs in geopolitics has led to wrong decisions. One of these goes back to 2003, to the second Iraq war when Colin Powell, who was then in charge of US diplomacy, brought forward photographs that "proved" that the Iraqi administration was in possession of weapons of mass destruction or otherwise dangerous chemical weapons. These photographs were actually confusing and impossible to interpret, and should have been explained by specialists. Still, they were taken as evidence that Saddam Hussein was in the possession of those weapons. Today we know that was not true, as Powell himself admitted later on. An image, then, functions as a tool which legitimizes a discourse.

A striking example of geopolitical representation is the photograph of 3-year-old Aylan Kurdi, a Kurdish child who perished on the Turkish shore in Bodrum on September 2, 2015. This image (see Fig. 1) (1) propelled Germany to drastically change its reception policy towards migrants (2) detonated outrage in Europe, which until then had remained relatively indifferent to anti-immigration policies (3) began a profound discussion in various European countries which denounced that 


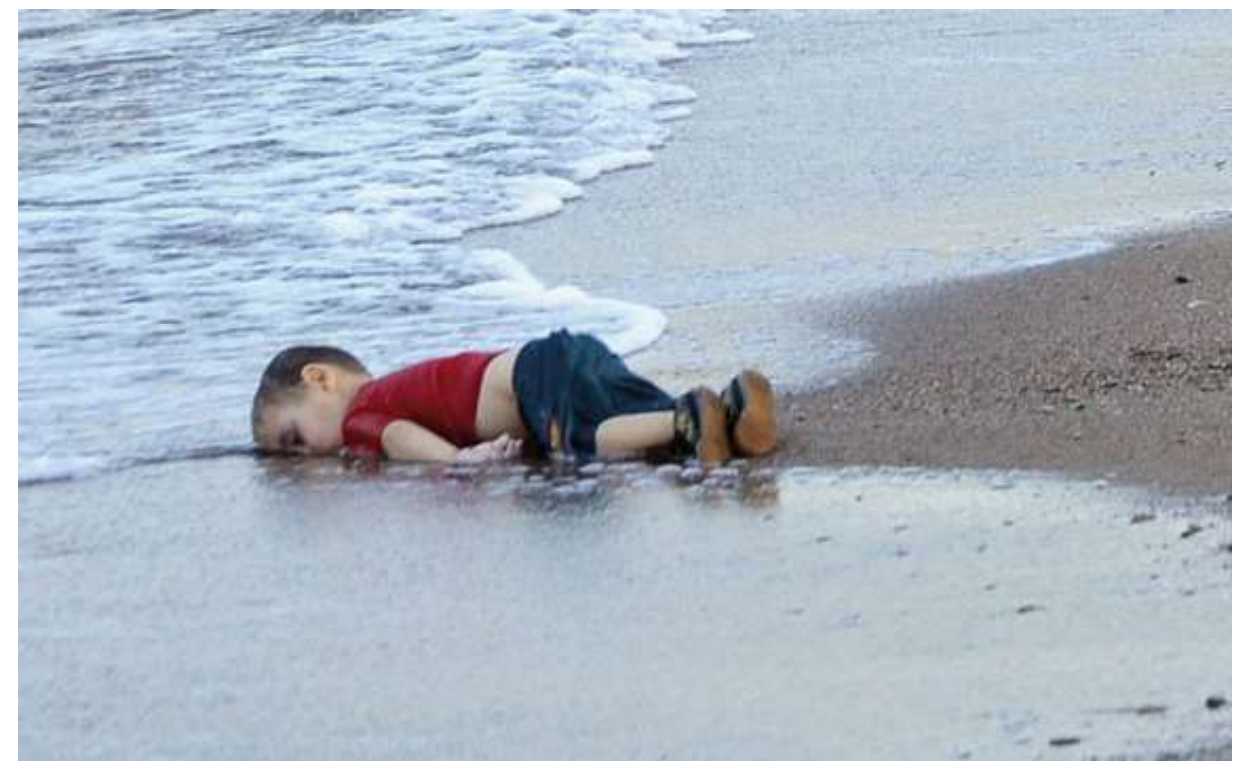

Fig. 1 The body of Aylan Kurdy on the shore of Bodrum (Turkey) on September 2, 2015 (c) ANSA, Italy

Fig. 2 Pierre Samson's drawing represents a variation of Aylan Kurdi's photograph. (C) Pierre Samson

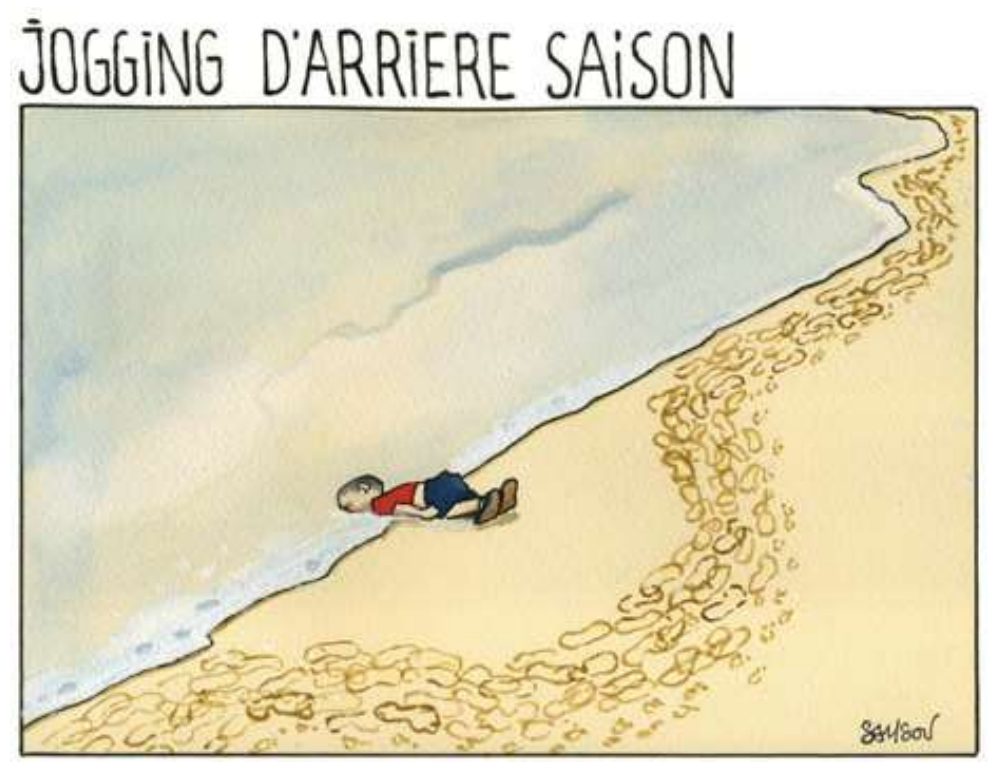

indifference. That photo perhaps only meant to show the tragedy of a father who lost his son on a coastline very close to our homes, and, what is more, a popular vacation spot. Instead, in the eye of the thousands of people who have seen it, it has become vested with a deeper meaning. Pierre Samson, illustrator and caricaturist for several French periodicals, came up with a variation of the sadly famous shot of Aylan Kurdi, he reproduced the photograph in every detail while also drawing runners' footprints around the body as if they were continuing to jog on undisturbed (See Fig. 2). This illustration indicted the European widespread apathy to the tragedy of migrants. Another example of how an image can be viewed through a lens that was certainly not originally intended is the photograph portraying Mohammed Shohayet, a 16-month-old Rohingya child, drowned in mud while he fled Myanmar for 
Bangladesh with his mother and brothers to escape persecution by Myanmar military forces. Mohammed was called immediately "the Rohingya Aylan Kurdi" (Wright 2017) by directly linking the two tragedies, albeit the reasons for the move were as dissimilar as the situations and places. The CNN headline was not enough, evidently, since other media have published the two photographs side by side so that the discourse summarized in the $\mathrm{CNN}$ headline produced an emotional impact without taking into account that these two events had actually taken place in two very distant parts of the world and 2 years apart from each other (AGI 2017).

Manipulation of images therefore does imply digital changes (which are not exactly recent developments), though not exclusively. The main form of image manipulation is found in the discourse which accompanies the image, and including works of art. It is not uncommon for archaeological ruins, which are only echoes of art, to be considered "works of art" because, as cultural reference, they symbolize the past and national identity. Several scholars have highlighted how monuments actually become "monuments to the history of art" (Riegl 2017) to the point that attempting to distinguish between historical monument and artistic monument is arduous because the two become one along the way. On the other hand, we are well aware of how artistic heritage becomes historical heritage of a specific history which various political actors have contributed to building, an artistic/historic heritage made of symbols that have assembled the memory and identity of a community, ousting any detail the political actors themselves decide to oust. This is what Jacinto Lageira defines as "possessing plasticity and historicity at the same time" (Lageira 2016); images of any kind fit nicely under this representational category because they are never neutral. The choice of images that we decide to bring forward or the choice of monuments that we propose as the pillars of a given identity become a choice on which values we want to represent to understand which society we want to create, and consequently "which images from our history we want create and showcase" (Lageira 2016, p. 14).

\subsection{The Landscape}

In the geographical imaginary, landscapes are perhaps what comes to mind faster, and something which at the same time has caused loud debates for decades on the object they represent, and how to observe it. But why is this important in Geopolitics?

When Landscapes became object of pictorial representation, they were perceived as something one may observe passively, thus objectifying the landscape as a portion of nature (Farinelli 2009). This perception, then, includes a subject (the observer) who observes an object (the landscape) by a medium (the eyes); however, it makes several further assumptions: first of all, the landscape-object is seen as something we observe as a by-product of another "entity", that is, nature. However, this perception has changed, in fact nowadays the Landscape is no longer viewed as a derivative of nature, instead it is always "anthropized": it is humans who make the landscape, with 
their intervention on it. It is difficult to imagine a corner of the earth where humans have not become involved in this dynamic by simple actions or by expressly "preserving" the landscape (Gambi 1972). In many cases, landscape architects today intervene on a damaged terrain to bring it back to its previous conditions; consequently, buildings are torn down, or vegetation is uprooted because it may not be native to the "original" landscape they want to reproduce. Clearly this landscape "anthropization" acquires even more relevance if we think of the territory where we live daily, which may be neither wild nor protected, instead it is the backdrop for socio-economic activities, which is clearly a human construction (Casti 2009; Spagnoli 2012).

In European culture the concept of Landscape relies on three assumptions: it is a portion of a territory, it is perceived only visually and it forms part of a duality where the subject is the observer, and the landscape is the object (Jullien 2014). The first assumption already helps us decipher the weight of choice on the portion of territory which we observe or present: which landscape would we like to propose as representative of something (an identity, a value, a culture)? The second assumption, according to Jullien, raises some doubts. Truly, if we reduce the landscape to something seen through the eyes and nothing more, it loses its "meaningfulness". The landscape is a resource, especially in geopolitics, which becomes instrumentalized as a representation in the hands of the political actor to justify a vision and a strategy. In his study, Jullien quotes Yves Lacoste' thoughts on landscape as the backdrop for military action, which is to be observed as a reminder to remain vigilant, thus adding a tactical feature to the aesthetic qualities of Landscape. Lacoste is even more precise in his work as he reflects on his own geopolitical approach: "[...] Effectively looking at a landscape implements a conception of geography linked to action and it is also war people who first began to look carefully at the images of the landscapes" (Lacoste 2009, p. 288).

The political importance of the Landscape is now enshrined in the Europe of Landscape Convention which defines it as an "area whose character is the result of the action and interaction of natural and/or human factors". The Convention allows an important awareness of what is the "landscape" even if initially it was mainly aimed at preservation. But it no longer distinguishes the Landscape as something beautiful, but any portion of territory is a landscape that deserves attention, study, analysis. This is particularly due to the fact that through it we can understand the action of man (Europe 2000).

As for all things geographical, the landscape is always reliant on the interpretation of the viewer, which in turn is planted so firmly on subjective and individual values such as perceptions, emotions, the observer' own identity. We may add to that a cultural perception, as members of a community to which we feel we belong, and with which we share different values. This leads us to identify various characteristics, for example, how the landscape is portrayed in different parts of the world. For example, a thousand-year-old landscape painted in China varies considerably from a Renaissance landscape painted in Italy. In his study, Jullien underlines that the Landscape initially only fills the gaps of a painting, much like a backdrop would to the main subject of a picture. Only later will the landscape become an object of its own representation, in particular during romanticism and later in impressionism. In 
Chinese painting, until recently, the landscape archetype was rural, though not reflecting the current real-world conditions of any Chinese rural area, where a population composed mostly of land workers lived and worked in small cultivation lots. On the contrary, paintings of landscape are synthesized to mountains and rivers with misty ponds. In comparison to Europe's heavily urbanized landscapes, the Chinese example is still very rural landscape, which points to the fact that the People's Republic of China was still experiencing a transition from the countryside to the city, which Europe had already concluded. Interestingly the Chinese work for landscape is shanshui, whose literal meaning is mountain-rivers; Chinese artists had simply erased what they saw in a landscape in their daily life, leaving instead what was the synthesis of 'rising towards the sky' (Frémont 2005, p. 111) (See Figs. 3 and 4).

Landscape has also been an instrument for conveying a certain identity of oneself as a territory in the most concrete sense. Thus, the Hudson River School had adopted pictorial representations where nature was unique affirmation, the only element of "glory" as to define the territory of the United States of America, a new land. This as opposed to the old Europe, where the landscapes, at the same time, were, instead, heavily anthropized. A representation of a "new birth" that wiped out all the "old" that European opponents could represent (See Fig. 5).

The image of a landscape becomes a real political construction, where action is also taken to modify it and adapt it to what we want to represent. It is such a social and identity representation that the contents are selected to compose an "ideal landscape" that best embodies the values of the political actor who wants to use it. A prime example are the posters used during the French presidential election campaigns. In this case, I refer to François Mitterrand's posters from 1965, and from his winning campaign in 1981, when for the first time in French history a left-wing president took office. The election poster must summarize key campaign principles, and in 1965 France was in the midst of the transition from agriculture to industry. For this reason, the candidate's image does not rest on a background of rolling hills and villages but next to an electricity pylon against a flat landscape, with industrial chimneys: "a modern France", the poster reads. In other words, this Landscape represents a land may have been agricultural in the past but which is becoming industrialized in the present (See Fig. 6). Today those chimneys would horrify any voter.

The 1981 poster is remarkably different. In the French imaginary, their country is not Paris but small villages, a bucolic landscape with a small church as the community's meeting point: a peaceful strength. The fact that a leftist president, also supported by members of the French communist party, could come to power, should not have frightened. The 1981 campaign poster was reassuring towards those who sought symbols of the French identity. On the bell tower of the church there should actually have been a cross, of course, but the Mitterrand campaign committee, with the participation of the Communists too, found it 'too Catholic', too religious-looking for the secular principles of the Republic. So, it was decided to delete it (See Fig. 7). Ultimately and practically, you take a symbolic landscape and adapt it to the representation that you want to give. 


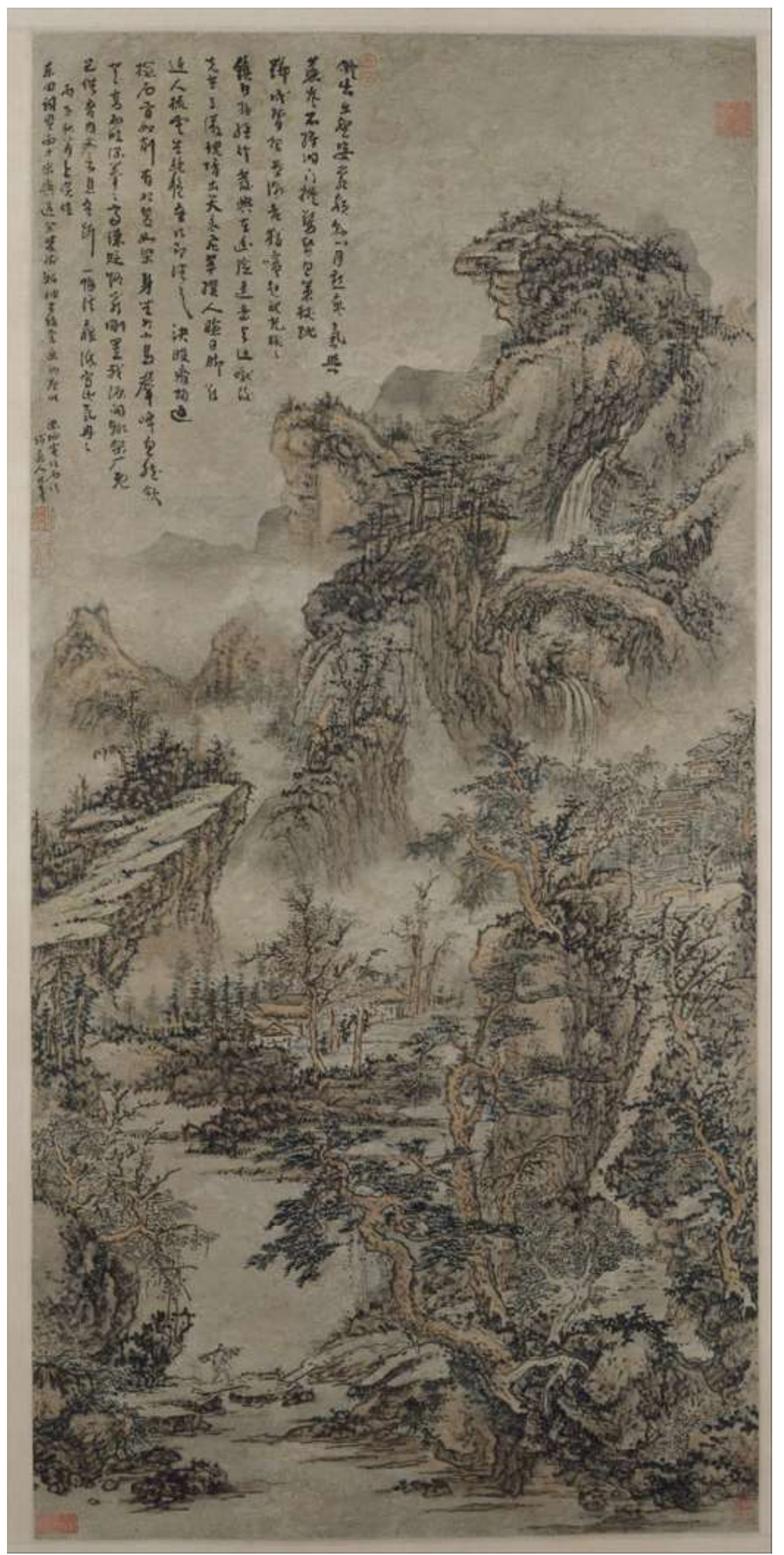

Fig. 3 Kuncan, Wooded Mountains at Dusk, China, Qing dynasty (1644-1911). Source: The Metropolitan Museum of Art (metmuseum.org), (C) Public Domain 


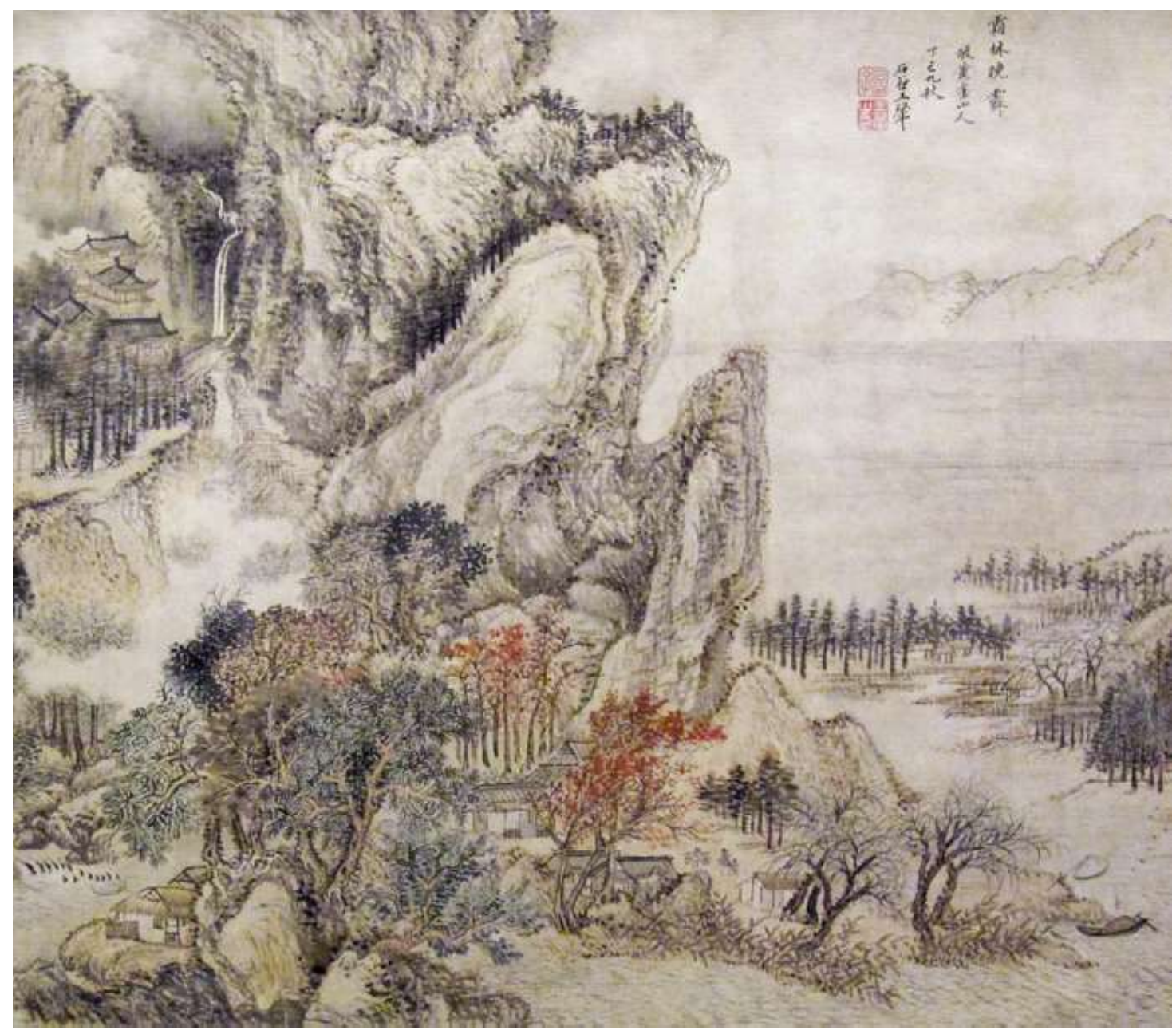

Fig. 4 Wang Hui, Landscapes after old masters, China, Qing dynasty (1644-1911). Source: The Metropolitan Museum of Art (metmuseum.org), (C) Public Domain

In photography or in painting, then, the landscape is not only a product to be studied as the fruit of human work on a given territory but also becomes a representation of a given vision by the same society. What makes Landscape a symbol of a society is its "fixed" perception as given in nature to permanently inscribe the "sign" of a given community; on the other hand, we know well that Landscape, like culture, like language, is evolutionary, the result of the changes caused by the interaction between strata of society and with the territory they inhabit.

In Italy, mosques have always been hidden in urban landscapes, very rarely do they present clearly visible distinctive signs. For example, the Portoghesi Mosque in Rome is never featured in images of the city's urban landscapes, yet, located in Acqua Acetosa, between Villa Ada and the Tiber, it could be an easy choice. It's never featured even in fictitious landscapes which compose images of contemporary heritage, which instead always showcase the Auditorium by Renzo Piano. The Portoghesi Mosque is the largest in the western world and it's located in the capital of Christianity, and therefore of great symbolic value. It is not even featured in landscape photographs of the Parioli district, where it is located. 


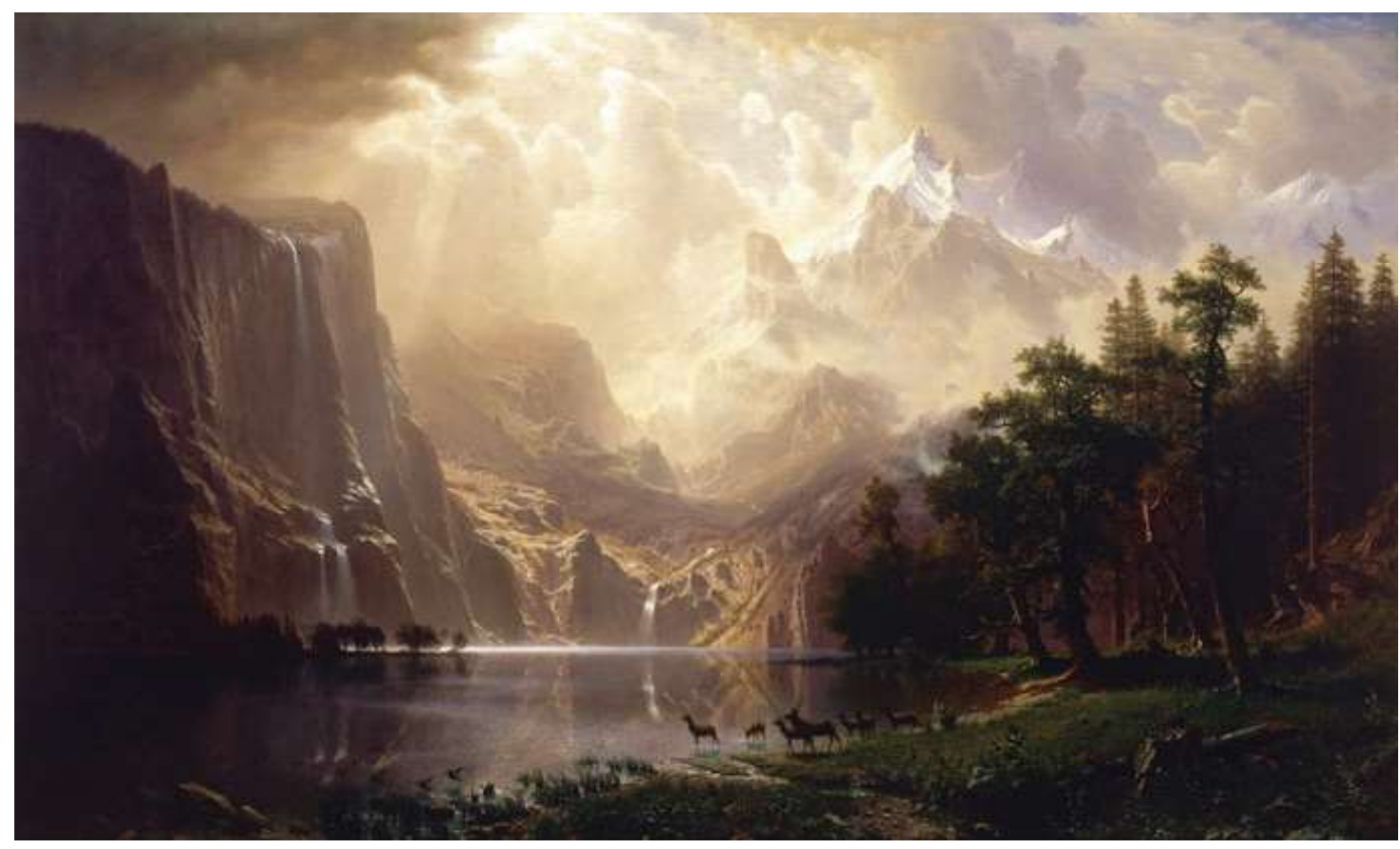

Fig. 5 Among the Sierra Nevada, California. Source: Smithsonian American Art Museum, (C) Public Domain

The selection of the contents of a Landscape participates in the rewriting of history. Examples abound from the end of World War II, when the Japanese attempted to recompose their history going beyond the first half of the 1900s and eliminating events related to the war, colonization, enslavement or invasions. The 1995 Paradise Lost exhibition at the Yokohama Museum critiqued the identity that the right-wing Japanese culture was trying to reconstitute. Julia Adenay Thomas shows how something harmless becomes an instrument of resistance, if a careful interpretation is constructed (2012). Adenay Thomas brings up several examples, such as the painting by Aimatsu (Landscape with an eye) and that by O Chi-ho (South-Facing House), both mixing different visions. O Chi-ho, a Korean artist trained in Japan highlights the limits of the national identity which extremists of the Japanese right were working on. The Yokohama Museum exhibition showcased paintings by different artists, some of whom were impressionists, like the Japanese Aimatsu, who for Adenay Thomas represented "[...] a challenge to identity, synthesizing international surrealism with Japan's indigenous traditions" (2012, p. 338). Identity, in its various possible definitions, stands at the center of the representation that is made in a landscape, be it photographic or pictorial. In the late 80s and early 90s, Japan was torn between an apologetic government for the aggressions they had committed in the past, and an extremist right wing who did not tolerate this vision, who did not believe had to deny anything of his past; identity was really the object in dispute. Adenay Thomas uses "revelatory" in connection with the "identity logic" strategy by right-wing government officials and extremist associations (2012, p. 340). This is particularly pertinent because it proves the landscape's dual function as both commemorative and historical, as a document of a certain past, and therefore 


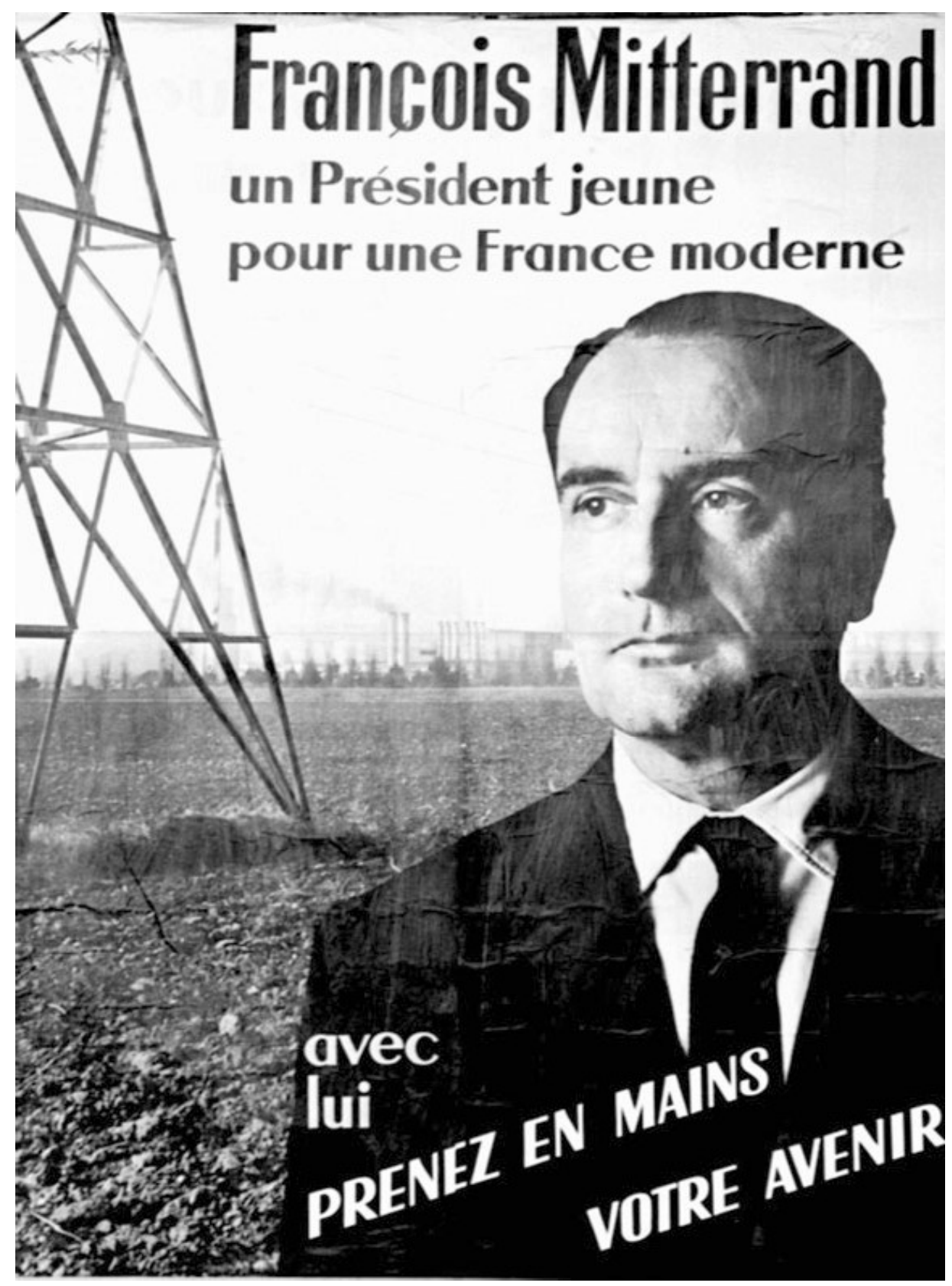

Fig. 6 Election poster of François Mitterrand for Presidential campaign of 1965. Source: Institut François Mitterrand, (C) Public Domain

a sort of mediation between memory and history. Another fundamental aspect of geopolitics and of representation: communication. The paintings used in Lost Paradise are certainly important as an artistic object that communicate a certain vision. The exhibit itself has a representation "line which clearly opposes the rightwing's 'line' by pushing beyond the borders of national Japan, as if to better integrate it with the history of the entire regional area. Here, both the museum itself and the exhibition bring forward a Geopolitical 'representation line". Similar examples have happened in Africa, where many museums were established to strengthen the role of one ethnic group at the expense of another, possession rights over a river 


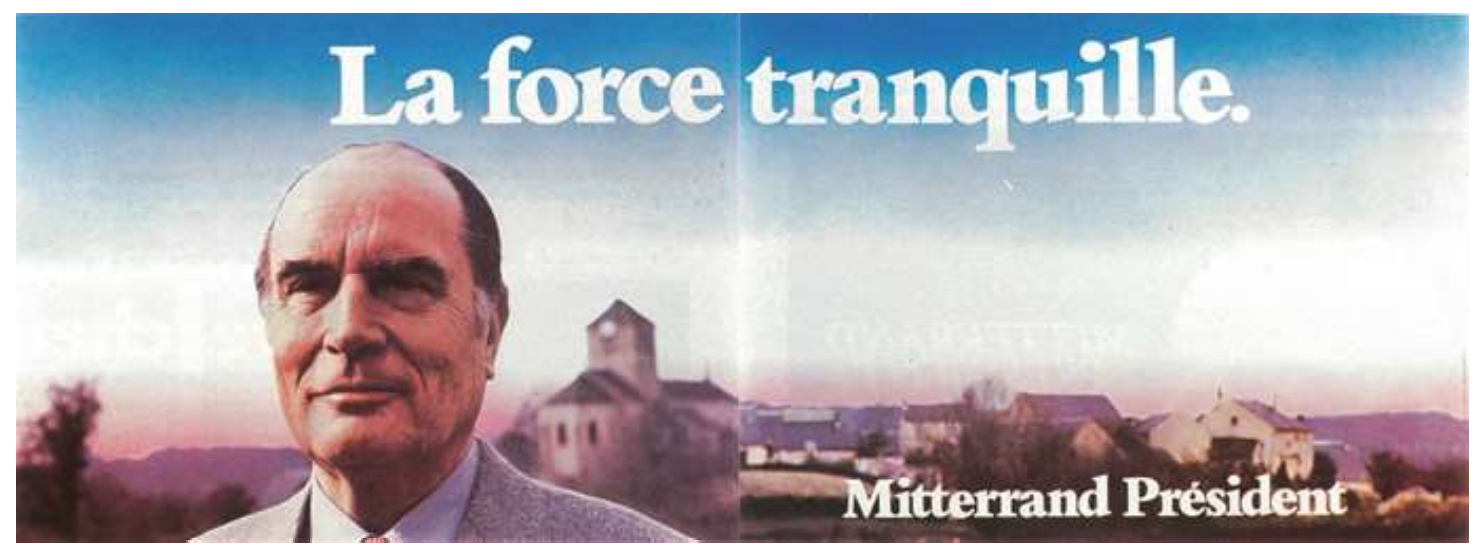

Fig. 7 Election poster of François Mitterrand for Presidential campaign of 1981. Source: Institut François Mitterrand, (C) Public Domain

have been affirmed with collections of specific objects representing a given ethnicity; but when this ethnic group became a minority, the majority to erased the traces of the previous ethnic group inside the museum for their benefit (Bondaz 2014).

\section{Conclusions}

Geopolitics as a discipline which studies disputes between political actors on the becoming of a given territory is made above all of communication, of narration rather than of armed conflict. Whichever definition we take into consideration of the ones I have outlined here, today no political actor can afford a territorial intervention strategy without a communication strategy which legitimizes it. We take ownership of the territory with multiple tools and the first appropriation may be that toponyms, which call the territory into existence based the name we impose on it. However, images are equally important particularly today in a society where production and circulation of images continues intensely. These images are manipulated in a way unforeseeably by their authors. Moreover, the image which would seem the most innocuous, the Landscape, has instead enormous powers: of appropriation, for example, in terms of physical "construction", meaning "what we are going to build on it"-buildings, bridges, monuments, or what we destroy to "rebuild"; and of suggestion, what Adeany Thomas has called "between memory and history". In this manner, images of landscapes are chosen based on what it will represent, possibly eliminating what should not be shown or simply changing the frame. As a semiotic object, representation is therefore one of the pillars of geopolitical reasoning, and it is never objective or innocent. Neither are images.

Acknowledgments I must thank my colleague Luisa Spagnoli, from the Institute for the History of Mediterranean Europe, National Research Council, for making me think on other work that I had not considered. I have also to thank Fabio Di Carlo, precious colleague of the University La Sapienza of Rome, Architect of the Landscape, who as always helped me to review my work 
with valuable advice. I owe a special thanks instead to Philippe Malgouyres, Chief Conservator at the Louvre Museum who, with a 30-year friendship, never ceases to help me and, in this specific case, opened new windows to appreciate what I would surely have overlooked.

\section{References}

Adenay Th J (2012) Landscape's mediation between history and memory: a visual approach to Japan's past. In: Asato I, McDonald A, Ming T (eds) Art and War in Japan and its Empire: 19311960. Brill, Leiden, pp 334-349

AGI (2017) Il rohingya 'Aylan Kurdi'. A 16 mesi muore nel fango per fuggire alla repressione, 5 January. https://www.agi.it/estero/profughirohingya_alan_kurdi_a_16_mesi_muore_nel_ fango_per_fuggire_alle_persecuzioni_birmania_mohammed-1347979/news/2017-01-05/. Accessed 18 May 2020

Agnew J (1998) Geopolitics: re-visioning world politics. Routledge, London

Bondaz J (2014) Politics of museum objects in West Africa. Anthropologie et société 38(3):95-111. https://doi.org/10.7202/1029020ar

Casti E (2009) Introduzione. L'invenzione del paesaggio: costruire, rappresentare, pianificare l'Altrove. In: Casti E (ed) Alla ricerca del paesaggio nelle rappresentazioni dell'Altrove. L'Harmattan, Torino, pp 11-19

Erodotus (2000) Storie: La Persia, Libro III. Mondadori, Milano

European Treaty Series - No. 176 European Landscape Convention, Florence, 20.X.2000

Farinelli F (2009) La crisi della ragione cartografica. Einaudi, Torino

Frémont A (2005) Aimez-vous la géographie? Flammarion, Paris

Gambi L (1972) I valori storici dei quadri ambientali. In: Romano R, Vivanti C (eds) Storia d'Italia, vol 1. I caratteri originali. Einaudi, Torino, pp 3-57

Harley JB (1988) Maps, knowledge, and power. In: Cosgrove D, Daniels S (eds) The iconography of landscape: essays on the symbolic representation, design and use of past environments. Cambridge University Press, Cambridge, pp 277-312

Jullien F (2014) Vivre de paysage ou L'impensé de la Raison. Gallimard, Paris

Korzybski A (1998) Une carte n'est pas le territoire. Editions de l'éclat, Paris

Lacoste Y (1976) La Géographie ça sert d'abord à faire la Guerre. Maspero, Paris

Lacoste Y (1993) Dictionnaire de Géopolitique. Flammarion, Paris

Lacoste Y (1998) Vive la Nation. Fayard, Paris

Lacoste Y (2009) De la Géopolitique aux Paysages. Dictionnaire de la géographie. Armand Colin, Paris

Lageira J (2016) Ouverture. In: Lageira J Usages Géopolitique des images. Éditions Textuel, Paris, pp 5-15

Loyer B (2019) Géopolitique. Méthodes et concepts. Armand Colin, Paris

Ó Tuathail G (1994) The critical reading/writing of geopolitics: re-reading/writing Wittfogel, Bowman and Lacoste. Prog Human Geography 18(3):313-332

Ó Tuathail G, Agnew J (1992) Geopolitics and discourse. Practical geopolitical reasoning in American foreign policy. Political Geography 11(2):190-204

O'Loughlin J (1994) Dictionnary of geopolitics. Greenwood Press, Westport

Pickles J (2004) A history of spaces. Cartographic reason, mapping and the geo-coded world. Routledge, London

Riegl A (2017) Il culto moderno dei monumenti. Il suo carattere e i suoi inizi. Abscondita, Milano

Said EW (1978) Orientalism. Pantheon Books, New York 
Spagnoli L (2012) Rappresentare e "Agire" il Paesaggio tra sostenibilità e nuova progettualità. Un Itinerario geografico, Consiglio Nazionale delle Ricerche. Istituto di Storia dell'Europa Mediterranea, Cagliari

Strabo (2002) Il Medio Oriente di Strabone. Libro XVI della "Geografia". Edilibri, Milano

Wood D (1992) The power of maps. Guilford Press, New York

Wright R (2017) 'The Rohingya Alan Kurdi': Will the world take notice now? CNN, 3 March. https://edition.cnn.com/2017/01/03/asia/myanmar-alan-kurdi/index.html. Accessed 18 May 2020 